\title{
Colonic lipomas an uncommon cause of intussusception in adult patients: report of three cases and literature review
}

\author{
Lipomas de colon una causa poco común de intususcepción en pacientes adultos:
} Reporte de tres casos y revisión de la literatura

\author{
Francisco E. Álvarez-Bautista, Paulina Moctezuma-Velázquez, Julio C. Cisneros-Correa, \\ Jorge L. Aguilar- Frasco, Alina Vélez-Valle, Omar Vergara-Fernández y Noel Salgado-Nesme* \\ Division of Colorectal Surgery, Instituto Nacional de Ciencias Médicas y Nutrición "Salvador Zubirán", Mexico City, Mexico
}

\begin{abstract}
Colonic lipomas are infrequent, benign, non-epithelial, fatty neoplasms. Most of the colonic lipomas are asymptomatic, but around $25 \%$ of patients may develop symptoms. Nowadays, surgical resection of the involved segment is the treatment of choice. We report three cases of colonic intussusceptions caused by colonic lipomas in adult patients. The patients underwent surgical resection, and the diagnosis was confirmed by histopathological examination of the specimens.
\end{abstract}

Key words: Colonic lipomas. Intussusception.

\section{Resumen}

Los lipomas colónicos son neoplasias benignas, adiposas, no epiteliales poco frecuentes. La mayoría de los lipomas de colon son asintomáticos, pero alrededor del $25 \%$ de los pacientes pueden desarrollar síntomas. En la actualidad, la resección quirúrgica del segmento afectado es el tratamiento de elección. Presentamos tres casos de intususcepción intestinal secundaria a lipomas colónicos en pacientes adultos. Los pacientes fueron sometidos a resección quirúrgica y el diagnóstico se confirmó mediante examen histopatológico.

Palabras clave: Lipomas colónicos. Intususcepción.

\section{Introduction}

Colonic lipomas (CLs) are benign, non-epithelial, fatty neoplasms with an incidence of $0.2 \%$ to $4.4 \%$. (1) Although infrequent, they are the second most common benign tumor of the colon, and $65-75 \%$ of the lipomas of the gastrointestinal tract occur in the colon, being the most frequently affected site $^{2}$. (2) Mostly they are asymptomatic, and need no treatment; but around $25 \%$ of the cases may develop symptoms including bowel obstruction and intussusception ${ }^{3}(3)$; those larger than $4 \mathrm{~cm}$ are considered giant and may be symptomatic in $75 \%$ of cases $^{4}$. (4)

\section{Correspondence:}

*Noel Salgado-Nesme,

Vasco de Quiroga, 15

Ciudad de México, México

Date of reception: 17-01-2021

Telephone: +5215554870900

E-mail: noelsalgadonesme@yahoo.com.mx

0009-7411/@ 2021 Academia Mexicana de Cirugía. Published by Permanyer. This is an open access article under the terms of the CC BY-NC-ND license (http://creativecommons.org/licenses/by-nc-nd/4.0/).
Date of acceptance: 27-02-2021

DOI: $10.24875 / C I R U .21000047$
Cir Cir. 2021;89(S2):9-12

Contents available at PubMed www.cirugiaycirujanos.com
of the CC BY-NC-ND license (n) 
Intestinal conditions, such as intraluminal lesions alter bowel peristalsis and serve as a lead point to create an intussusception ${ }^{5}(5)$. Although intestinal intussusception is a relatively common cause of bowel obstruction in children, it is uncommon in the adult population, causing $<1 \%$ of bowel obstructions ${ }^{5}$. (5)

We report three cases of CLs in adult patients presenting with colo-colonic intussusception that required surgical management, the diagnosis was confirmed by histopathological examination of the specimens.

\section{Case 1}

A 50-year-old male patient with no comorbidities complained of intermittent abdominal pain, change in bowel habits with constipation and narrow stools, associated with emesis, weight loss, and bloody stools. Colonoscopy and computed tomography revealed a $5.9 \times 5.4 \times 4.1 \mathrm{~cm}$ mass located in the hepatic flexure of the colon. Right hemicolectomy with ileotransverse anastomosis was performed. He made an uneventful postoperative recovery. (Figs. 1-2)

\section{Case 2}

A 42-year-old male patient with a history of systemic arterial hypertension was referred to our surgical outpatient clinic with a one-year history of intermittent abdominal distension, diffuse abdominal pain, constipation, bloody stools, and weight loss. A colonoscopy showed a $3.5 \times 2.7 \times 2.6 \mathrm{~cm}$ lesion in the transverse colon, on computed tomography an hypodense lesion with fat density was found, during colonoscopy the lipoma was ligated with an endo-loop to block the blood supply for ischemic resection; however, the lesion just developed ischemic changes but remained in place, so the patient was taken to surgery for segmental resection of the transverse colon. The patient progressed favorably, and was discharged without complications. (Figs. 3-4)

\section{Case 3}

A 54-year-old female patient with no comorbidities was admitted to the emergency department, with an exacerbation of a chronic and intermittent diffuse abdominal pain, associated with change in bowel habits, nausea and vomiting.

On physical examination, the patient had soft abdomen with diffuse tenderness, without signs of peritoneal irritation. Abdominal computed tomography showed an ascending colo-colonic intussusception
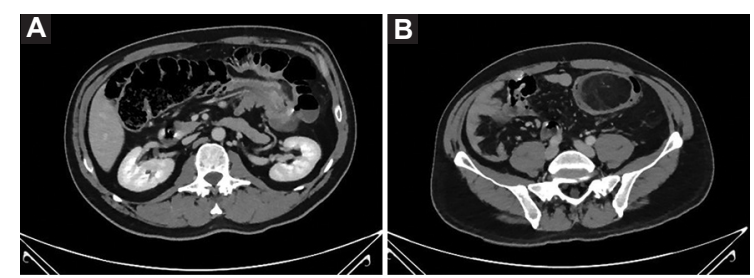

Figure 1. A: colo-colonic intussusception. B: colonic lipoma showing heterogeneous radiographic density.

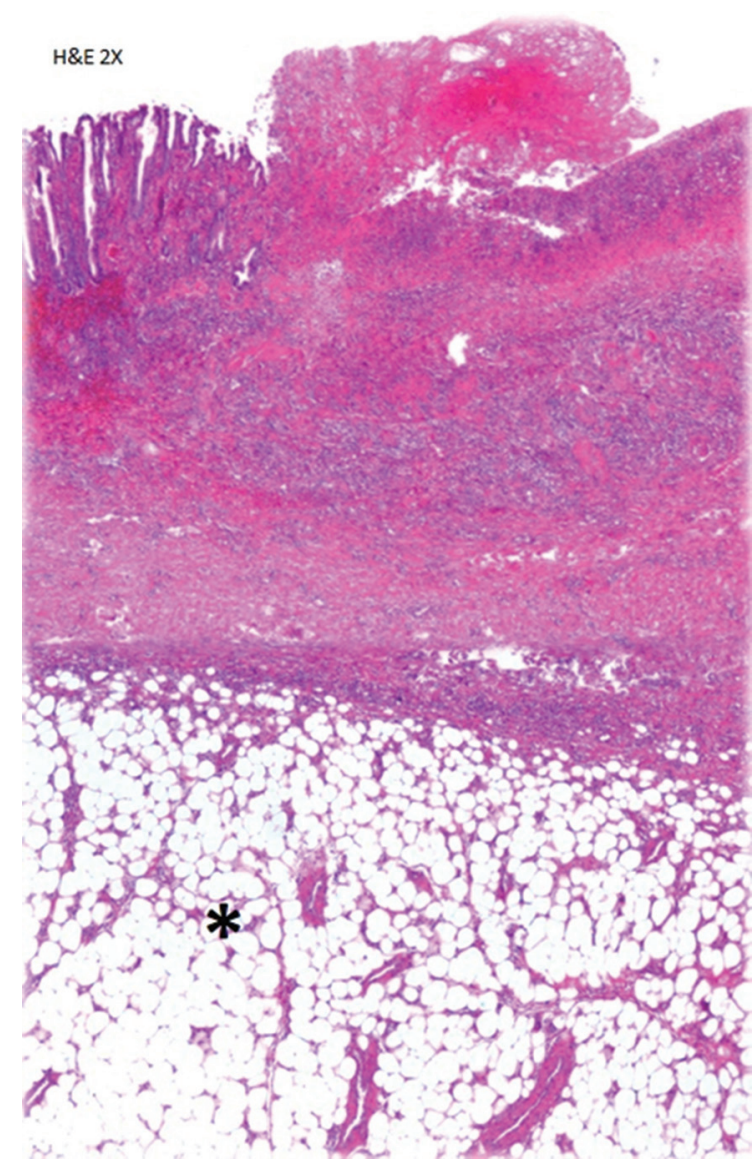

Figure 2. Histopathologic examination of the specimen showed a tumor composed of mature adipose tissue in the submucosa (*).

causing partial obstruction due to an intraluminal lipomatous mass of $5.1 \times 5.5 \times 3.4 \mathrm{~cm}$. A colonoscopy showed a subepithelial lesion located at the hepatic flexure of the colon with benign macroscopic characteristics. The patient was taken to right hemicolectomy with ileotransverse anastomosis and was discharged without complications (Figs. 5-6).

\section{Discussion}

Intussusception is common in children but infrequent in adults, around $95 \%$ of intussusceptions occur 

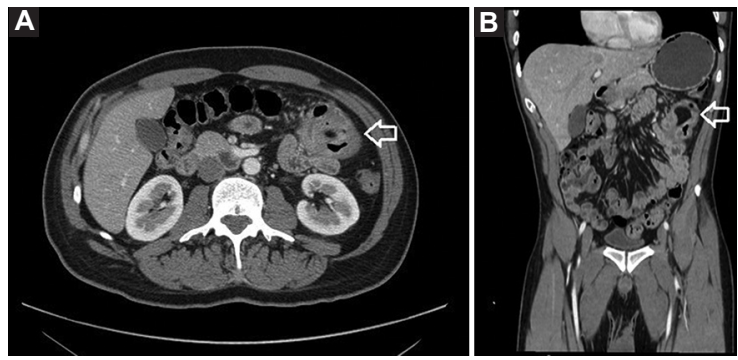

Figure 3. A: colo-colonic intussusception, the donut sign is shown (white arrow). B: characteristic fatty radiodensity of the lesion is shown (white arrow).

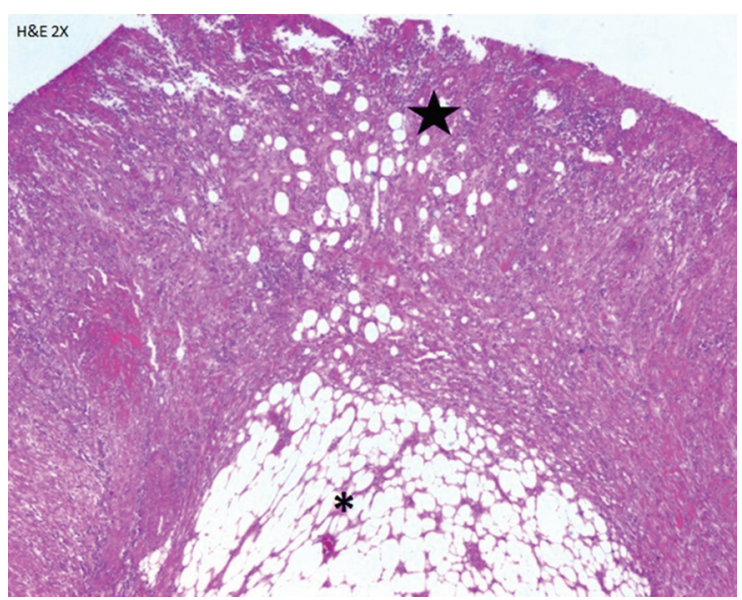

Figure 4. Ulcerated colonic mucosa (black star) and below it, in the submucosa a well circumscribed tumor composed of adipose tissue is identified.

in pediatric population and the remaining $5 \%$ occur in adults $^{6}(6)$, being the cause of $<1 \%$ of cases of intestinal obstruction ${ }^{5}(5)$; meanwhile, colo-colonic intussusception represents $17 \%$ of all intestinal intussusceptions in adults ${ }^{7}$. (7) In a retrospective review of 44 cases of intussusception in adults, Honjo et al. found 12 enteric intussusceptions, 6 ileocolic intussusceptions, 16 ileocecal intussusceptions, and 10 colonic intussusceptions, of the latter only 1 case was of benign etiology ${ }^{7}$. (7)

Colonic lipomas measuring $<2 \mathrm{~cm}$ are usually asymptomatic, whereas those of $>4 \mathrm{~cm}$ are symptomatic in $75 \%$ of the cases $^{8}$. (8) A review of the literature by Paskausas et al. analyzed 37 cases of CLs associated with intussusception, the ascending colon was the most frequently affected site ${ }^{9}$. (9)

An accurate preoperative diagnosis can be challenging since CLs have nonspecific clinical manifestations. Series of intussusception in adult patients report pain as the most common symptom (present in $71 \%$
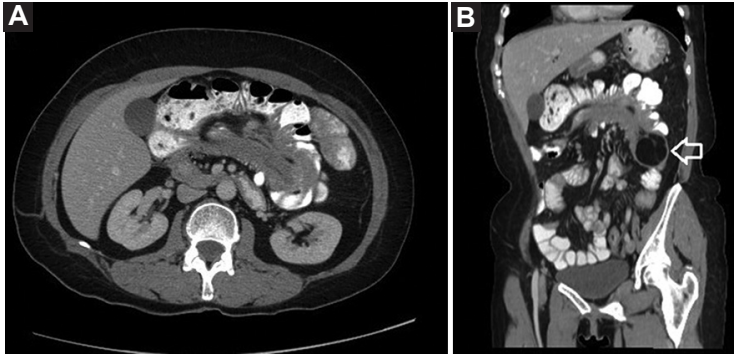

Figure 5. A: colo-colonic intussusception is shown. B: the lipomatous lesion that served as the lead point of intussusception is shown (white arrow).

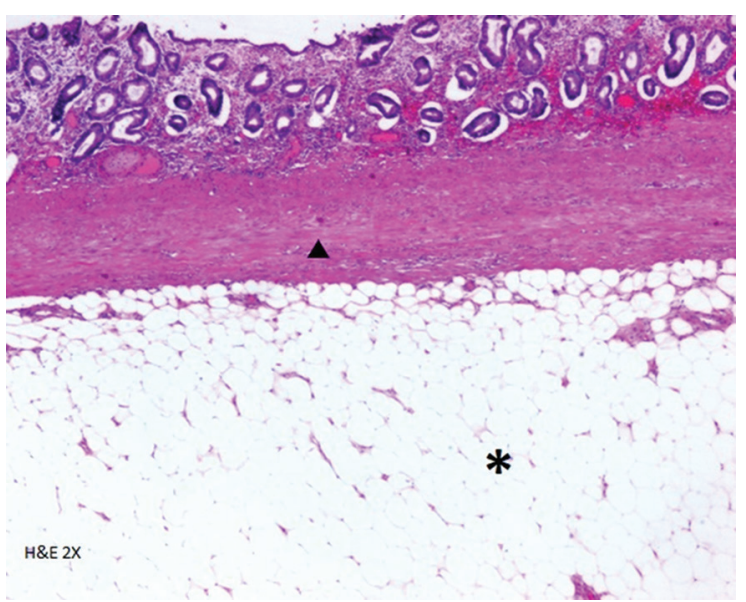

Figure 6. Under the thickened muscularis mucoa (black triangle) a tumor composed of mature adipose tissue is identified $\left({ }^{*}\right)$

to $90 \%$ of patients), and its intermittent characteristic favors a late diagnosis. Vomiting, and low gastrointestinal bleeding are the next most frequent ${ }^{10}$. (10)

Other symptoms include abnormal bowel habit, diarrhea, and anecdotally, patients may defecate an hemorrhagic tissue, due to the autoamputation of the lipoma ${ }^{11}$. (11)

In a review of adult intussusceptions by Azar et al., the mean duration of symptoms between onset and presentation was 37.4 days (range 1-365 days), and can be longer in patients with benign enteric lesions compared to those with malignant and colonic lesions ${ }^{5}$. (5)

Nowadays a great variety of diagnostic tools are available. Barium enemas show a filling defect, nonetheless, this finding is no specific for CLs. Computed tomography has been suggested as the preferred modality for diagnosing intussusception of CLs due to characteristic fatty densitometric values (-40 till -120 Hounsfield units $)^{12,13}$. $(12,13)$ However, intussuscepted lipomas may not demonstrate normal fat attenuation and may have heterogeneous appearance reflecting fat necrosis ${ }^{14}$. (14) 
Magnetic resonance is particularly able to detect fatty lesions because of typical tissue signal intensity on T1-weighted and fat-suppressed images. However, this imaging method is rarely used to approach this type of lesions.

Colonoscopy may show CLs in the form of a yellow elastic submucosal mass, but sometimes hemorrhage, necrosis, and mucosal ulceration may be seen ${ }^{15}$. (15)

Regarding treatment, the general agreement is that CLs $<2.0 \mathrm{~cm}$ in diameter are accessible for endoscopic management, while this is not recommended for lesions $>2.0 \mathrm{~cm}$ due to the risk of complications ${ }^{16}$. (16)

For those patients taken for surgical treatment, formal colectomy and limited colon resection are considered as adequate treatment modality, particularly in those cases with a confirmed preoperative diagnosis ${ }^{17}$. (17)

According to Jiang et al., surgical intervention is appropriate when the lipoma is $>4 \mathrm{~cm}$ in size; has associated intussusception and the patient is symptomatic, or when the lesion cannot be resected endoscopically ${ }^{18}$. (18) However, formal oncologic resections may be necessary in some cases if the diagnosis is uncertain.

The definitive diagnosis is obtained from a histopathological exam ${ }^{19}$. (19) There are no reports of malignant transformations of CLs. However, some may have pseudosarcomatous changes when examined ${ }^{20}$. (20)

\section{Conclusions}

As CLs are uncommon, the diagnosis requires a high index of suspicion, and should be included in the differential diagnosis of symptomatic bowel tumors. Although intussusception itself carries a good prognosis, the most important prognostic factor is the nature of the lesion leading to the process.

Currently, surgery is still the treatment of choice, which depends on lipoma size, location, patient's medical history, imaging, and intraoperative findings.

\section{Author contributions}

All authors contributed equally to this manuscript. All authors contributed to the final approval of the manuscript. Francisco Emmanuel Alvarez-Bautista is the article guarantor.

\section{Conflict of interest}

The authors declare that they have no conflicts of interest.
Informed consent was obtained for this case report. All identifying information has been removed from this case report to protect patient privacy.

\section{Ethical disclosures}

Protection of human and animal subjects. The authors declare that no experiments were performed on humans or animals for this study.

Confidentiality of data. The authors declare that they have followed the protocols of their work center on the publication of patient data.

Right to privacy and informed consent. The authors have obtained informed consent from the patients and/or subjects referred to in the article. This document is in the possession of the corresponding author.

\section{References}

1. Vecchio R, Ferrara M, Mosca F, Ignoto A, Latteri F. Lipomas of the large bowel. Eur J Surg. 1996 Nov;162(11):915-9.

2. Zhang H, Cong J-C, Chen C-S, Qiao L, Liu E-Q. Submucous colon lipoma: a case report and review of the literature. World $\mathrm{J}$ Gastroenterol. 2005 May;11(20):3167-9.

3. Huh KC, Lee TH, Kim SM, Im EH, Choi YW, Kim BK, et al. Intussuscepted sigmoid colonic lipoma mimicking carcinoma. Dig Dis Sci. 2006 Apr;51(4):791-5.

4. Bahadursingh AM, Robbins PL, Longo WE. Giant submucosal sigmoid colon lipoma. Am J Surg. 2003 Jul;186(1):81-2.

5. Azar T, Berger DL. Adult intussusception. Ann Surg. 1997 Aug;226(2):134-8.

6. Yalamarthi S, Smith RC. Adult intussusception: case reports and review of literature. Postgrad Med J. 2005 Mar;81(953):174-7.

7. Honjo $\mathrm{H}$, Mike M, Kusanagi $\mathrm{H}$, Kano N. Adult intussusception: a retrospective review. World J Surg. 2015 Jan;39(1):134-8.

8. Nallamothu G, Adler DG. Large colonic lipomas. Gastroenterol Hepatol (N Y). 2011 Jul;7(7):490-2.

9. Paškauskas S, Latkauskas T, Valeikaitè G, Paršeliūnas A, Svagždys S, Saladžinskas Z, et al. Colonic intussusception caused by colonic lipoma: a case report. Medicina (Kaunas). 2010;46(7):477-81.

10. Reijnen HA, Joosten $\mathrm{HJ}$, de Boer $\mathrm{HH}$. Diagnosis and treatment of adult intussusception. Am J Surg. $1989 \mathrm{Jul} ; 158(1): 25-8$.

11. Radhi JM. Lipoma of the colon: self amputation. Vol. 88, The American journal of gastroenterology. United States; 1993. p. 1981-2.

12. Gollub MJ. Colonic intussusception: clinical and radiographic features. AJR Am J Roentgenol. 2011 May;196(5):W580-5.

13. Triantopoulou C, Vassilaki A, Filippou D, Velonakis S, Dervenis C, KouIentianos E. Adult ileocolic intussusception secondary to a submucosal cecal lipoma. Abdom Imaging. 2004;29(4):426-8.

14. Buetow PC, Buck JL, Carr NJ, Pantongrag-Brown L, Ros PR, Cruess DF. Intussuscepted colonic lipomas: loss of fat attenuation on CT with pathologic correlation in 10 cases. Abdom Imaging. 1996;21(2):153-6.

15. Meghoo CAL, Cook PR, McDonough CA, Bowser LK, Waddell BE. Large colonic lipoma with mucosal ulceration mimicking carcinoma. Gastrointest Endosc. 2003 Sep;58(3):468-70.

16. Lazaraki G, Tragiannidis D, Xirou P, Nakos A, Pilpilidis I, Katsos I. Endoscopic resection of giant lipoma mimicking colonic neoplasm initially presenting with massive haemorrhage: a case report. Cases J. 2009 Mar;2:6462.

17. Nakagoe T, Sawai T, Tsuji T, Tanaka K, Nanashima A, Shibasaki S, et al. Minilaparotomy approach for removal of a large colonic lipoma: report of two cases. Surg Today. 2004;34(1):72-5.

18. Jiang L, Jiang L-S, Li F-Y, Ye H, Li N, Cheng N-S, et al. Giant submucosal lipoma located in the descending colon: a case report and review of the literature. World J Gastroenterol. 2007 Nov;13(42):5664-7.

19. Rogy MA, Mirza D, Berlakovich G, Winkelbauer F, Rauhs R. Submucous large-bowel lipomas--presentation and management. An 18-year study. Eur J Surg. 1991 Jan;157(1):51-5.

20. Snover DC. Atypical lipomas of the colon. Report of two cases with pseudomalignant features. Dis Colon Rectum. 1984 Jul;27(7):485-8. 